\title{
Lactoferrin Inhibits Platelet Production from Human Megakaryocytes in Vitro
}

\author{
Kuniko Matsumura-TaKeda,,${ }^{* a, b}$ Tatsuhiro Ishida, ${ }^{a}$ Shinji Sogo,${ }^{b}$ Yoshimasa Isakari, ${ }^{a, b}$ Takao TAKI, ${ }^{c}$ \\ Toshiki Sudo, ${ }^{b}$ and Hiroshi KIWADA ${ }^{a}$ \\ ${ }^{a}$ Department of Pharmacokinetics and Biopharmaceutics, Subdivision of Biopharmaceutical Sciences, Institute of Health \\ Biosciences, The University of Tokushima; 1-78-1 Sho-machi, Tokushima 770-8505, Japan: ${ }^{b}$ First Institute of New Drug \\ Discovery, Otsuka Pharmaceutical Co., Ltd.; ${ }^{c}$ Institute of Biomedical Innovation, Otsuka Pharmaceutical Co., Ltd.; \\ 463-10 Kagasuno, Kawauchi-cho, Tokushima 771-0192, Japan.
}

Received November 18, 2007; accepted January 9, 2008; published online January 18, 2008

The mechanism of megakaryopoiesis, proplatelet formation (PPF) and platelet (PLT) production is not fully elucidated. Lactoferrin (LF) has been reported to have many biological functions including cell proliferation and differentiation, and the LF receptor is present on megakaryocytic cells. In the present study, we examined the effect of human LF (hLF) on PLT production from primary megakaryocytes (MKs). At first, we developed a PLT production system derived from human $\mathrm{CD}^{+} 4^{+}$cells by thrombopoietin (TPO) stimulation. Because the number of proplatelets, PLTs and CD41 ${ }^{+}$MKs was remarkebly increased after day 5, we employed the TPO-induced $\mathrm{CD34}^{+}$cells on day 5. Then, the effect of hLF on PLT production from human primary MKs was examined. In the range of 3-30 $\mu \mathrm{g} / \mathrm{ml}$, hLF significantly inhibited PLT production up to about $60 \%$. However, it did not significantly change the intensity of CD41 expression in MKs and the ploidy of MKs. In addition, it did not inhibit MK progenitors. These results suggest that LF directly inhibits PLT production from matured MKs, but does not inhibit megakaryopoiesis, including proliferation/maturation processes.

Key words megakaryocyte; platelet production; lactoferrin

Megakaryocytes (MKs), derived from hematopoietic stem cells and capable of releasing platelets (PLTs), are known to play an important role in hemostasis. The hematopoietic stem cells differentiate finally into MKs through megakaryocyte progenitors (colony-forming units-megakaryocyte [CFU-MK]). Then, the MKs mature accompanied by polyploidyzation and cytoplasmic maturation, and transform into a proplatelet formation (PPF) with cellular protrusions, which releases PLTs.

Lactoferrin (LF) is an $80-\mathrm{kDa}$ iron-binding glycoprotein, present in exocrine glands and secondary granules of neutrophilic leukocytes. It has been reported that LF receptors are expressed on intestine, ${ }^{1)}$ monocytes, ${ }^{2)}$ osteoblasts, ${ }^{3)}$ PHAactivated lymphocytes, ${ }^{4)}$ PLTs,${ }^{5)}$ and megakaryocytic cells. ${ }^{6)}$ LF levels in the serum of healthy donors are in the range of 2 to $7 \mu \mathrm{g} / \mathrm{ml}^{7)}$ On the other hand, in the case of inflammation and sepsis, the serum LF levels are significantly increased, ${ }^{7)}$ because LF is predominantly derived from and released during neutrophil activation. In addition, the expression of LF mRNA is enhanced in the bone marrow, ${ }^{8)}$ where hematopoiesis occurs and where there is a large reservoir of functional neutrophils. ${ }^{9,10)}$ To date, it has been reported that LF is involved in a variety of biological functions, such as cell growth and differentiation, ${ }^{11-13)}$ modulation of the inflammatory response, ${ }^{14)}$ anti-viral effects, ${ }^{15)}$ and regulation of myelopoiesis. ${ }^{16,17)}$ LF showed inhibitory effects on PLT aggregation by binding to the LF receptor which exists on the surface of PLTs, ${ }^{5)}$ but it is unclear whether LF can act on MKs though the LF receptor on the MKs. ${ }^{6}$ ) Therefore, we assume that LF may contribute to differentiation of MKs as well as being involved in cell proliferation and differentiation. ${ }^{11-13)}$

On the basis of the assumption, we examined whether LF is involved in each step of differentiation of MKs by investigating as follows: (1) MK proliferation: CFU-MK; (2) MK maturation: a MK specific maturation marker, CD41, expression and polyploidyzation of MKs; (3) PLT production: production of CD41 ${ }^{+}$PLTs from MKs. Here we show that LF directly inhibits production of PLTs derived from matured MKs, but inhibits neither CD41 expression, polyploidyzation nor CFU-MK.

\section{MATERIALS AND METHODS}

Reagents Human LF was purchased from SigmaAldrich (MO, U.S.A.). Recombinant human thrombopoietin (TPO), recombinant human interleukin-3 (IL-3) and recombinant human IL-6 were purchased from PeproTech (NJ, U.S.A.).

Rat monoclonal antibodies (mAbs) anti-mouse lineage antigens (CD4, CD8, TER119, CD71, CD11b, Gr-1), fluorescein isothiocyanate (FITC)-conjugated anti-mouse CD41 $\mathrm{mAb}$, phycoerythrin (PE)-conjugated anti-mouse CD45 $\mathrm{mAb}$, biotin-conjugated anti-mouse CD61 mAb, PE-conjugated anti-human $\mathrm{CD} 41 \mathrm{a} \mathrm{mAb}$, and PE-conjugated $\mathrm{IgG}_{1}$ were purchased from BD Pharmingen (CA, U.S.A.). Rat mAbs anti-mouse Thy1.2 and B220 were purchased from Cedarane (Ontario, Canada). Rat mAbs anti-F4/80 and $7 / 4$ were purchased from Serotec (NC, U.S.A.).

Cells Human bone marrow-derived $\mathrm{CD}_{3} 4^{+}$cells were obtained from Cambrex (NJ, U.S.A.) and maintained in serum-free medium (Stem Span SFEM, Stem cell Technologies, BC, Canada) supplemented with TPO $(10 \mathrm{ng} / \mathrm{ml})$ in $37^{\circ} \mathrm{C}, 5 \% \mathrm{CO}_{2}$ incubator.

Mouse $\mathrm{CD} 41^{+} / 61^{+}$fractions (mouse MK enriched fraction) were prepared from male BALB/C mice (6-10 weeks old) (Charles River Japan, Shiga, Japan) by modification of the method of our previous report. ${ }^{18)}$ Mouse lineage negative (lin ${ }^{-}: \mathrm{CD}^{-}, \mathrm{CD}^{-}$, Thy $1.2^{-}, \mathrm{B} 220^{-}, \mathrm{TER} 119^{-}, \mathrm{CD}^{-} 1^{-}$, $\mathrm{F} 4 / 80^{-}, \mathrm{CD} 11 \mathrm{~b}^{-}, \mathrm{Gr}-1^{-}$and $7 / 4^{-}$) cells were purified from 
the femoral marrow after incubation with a mixture of rat mAbs against lineage antigens and depletion $\operatorname{lin}^{+}$cells with Dynabeads coupled to a mouse antibody against rat immunoglobulin (Dynal, Oslo, Norway). Lin $^{-}$cells were stained with FITC-conjugated anti-mouse CD41 mAb and biotin-conjugated anti-mouse CD61 mAb, and CD61 was visualized by SA-QuantumRed ${ }^{\mathrm{TM}}$ (Sigma-Aldrich). Stained cells were sorted using a single laser (488-nm argon laser), EPICS-ELITE using ELITE 4.02 software (Beckman Coulter, FL, U.S.A.).

Effect of hLF on PLT Production from Human MKs Derived from $\mathrm{CD}_{4} 4^{+}$Cells $\mathrm{CD} 4^{+}$cells were cultured in serum-free media supplemented with TPO $(10 \mathrm{ng} / \mathrm{ml})$ alone to expand the MKs. After $5 \mathrm{~d}$, half of the supernatant was replaced with fresh media containing $\operatorname{hLF}(3,10,30 \mu \mathrm{g} / \mathrm{ml})$ supplemented with TPO ( $2 \mathrm{ng} / \mathrm{ml})$. On day 9 ( $4 \mathrm{~d}$ culture with $\mathrm{hLF}$ ), the cells in the culture media and those detached from the culture dish by treatment with EDTA-PBS (10 mM) were collected by centrifugation $\left(1710 \times \boldsymbol{g}, 10 \mathrm{~min}, 4{ }^{\circ} \mathrm{C}\right)$. The number of PLT in the collected cells was counted by using a flow cytometer, EPICS XL-MCL (Beckman Coulter). Briefly, the collected cells were stained with FITC-conjugated antihuman CD41 mAb. Twenty thousand units of Flow Count ${ }^{\mathrm{TM}}$ (Beckman Coulter) were added to the samples as internal control. To create a single PLT gate, human peripheral PLTs were stained in the same manner and analyzed. Then, the derived PLTs per 1000 units of FlowCount ${ }^{\mathrm{TM}}$ were enumerated as human $\mathrm{CD} 41^{+}$events with the same forward/side scatter properties as blood PLTs.

Cell Surface-Molecule Analysis To detect cell surface molecules of human MKs, flow cytometry was performed with an EPICS-ELITE flow cytometer (Beckman Coulter). After incubation of cells with the indicated antibodies for 30 min at $4{ }^{\circ} \mathrm{C}$, flow cytometric analysis was carried out.

MK Ploidy To determine MK ploidy, we co-stained cells with FITC-conjugated anti-human CD41a mAb (BD PharMingen) and propidium iodide (PI) (Sigma-Aldrich), and determined DNA content by two-color flow cytometry. ${ }^{19,20)}$ Briefly, the cells were stained with FITC-conjugated anti-human CD41a mAb, and then fixed and permeabilized with $1.85 \%$ formaldehyde neutral buffer solution (SigmaAldrich). After $10 \mathrm{~min}$ on ice, the cells were washed with PBS, and resuspended in PBS (pH 7.4) containing $4 \mathrm{~mm}$ sodium citrate, $10 \mu \mathrm{g} / \mathrm{ml}$ of PI, $200 \mu \mathrm{g} / \mathrm{ml}$ of RNase (Calbiochem, CA, U.S.A.), and $0.1 \%$ Triton X-100. The suspension was incubated for $4 \mathrm{~h}$ at $4{ }^{\circ} \mathrm{C}$ in the dark and filtered through a $70-\mu \mathrm{m}$ nylon filter to remove aggregates. Twocolor (FITC and PI) flow analysis was performed in a FACSCalibur analyzer with CELLQuest Pro software (Becton Dickinson, CA, U.S.A.).

CFU-MK Assay CFU-MK assay was performed using MegaCult-C Kit (Stem cell Technologies) according to the manufacturer's protocol. Human bone marrow (BM)-derived CD $34^{+}$cells $\left(2.5 \times 10^{3}\right)$ were cultured with hLF $(1-100$ $\mu \mathrm{g} / \mathrm{ml})$ in the presence of TPO $(50 \mathrm{ng} / \mathrm{ml})$, IL-3 $(10 \mathrm{ng} / \mathrm{ml})$ and IL-6 $(10 \mathrm{ng} / \mathrm{ml})$ for $12 \mathrm{~d}$ in collagen-based, semisolid medium. After fixation with cold acetone, MKs were visualized by alkaline phosphatase staining with peroxidase-conjugated anti-human CD41a mAb. Nuclei were stained with Evans blue. The number of CFU-MK was enumerated at day 12 using an inverted microscope, defined as aggregates con- taining at least three large refractile cells.

Histopathology and Cellular Analysis For histopathology, the femur including bone marrow from male BALB/C mouse ( 8 weeks old) were fixed in $10 \%$ neutrally buffered formalin, decalcified after fixation, embedded in paraffin, sectioned, stained with hematoxylin and eosin (H\&E), and examined microscopically. For cellular analysis, mouse MK enriched fraction's smear preparations were made using Cytospin2 (Thermo Shandon Inc., Pittsburgh, U.S.A.) and stained by the Wright-Giemsa method or the acetylcholine esterase staining method. ${ }^{21)} \mathrm{MKs}$ have giant cell size compared with the other cells, multilobulated nuclei, and their granules express red-brown in cells by the acetylcholine esterase staining. Neutrophils have segmented or band nuclei.

Stastical Analysis Statistical analysis was performed using 1-way ANOVA followed by 2-tailed Dunnett's test.

\section{RESULTS}

Human PLT Production System to Evaluate Effect of hLF To examine whether LF directly acts on MKs and consequently affects PLT production, we tried to develop a human PLT production system. We checked morphological changes, number of PLT produced and expression of CD41 (a MK-specific cell surface marker) on the TPO induced$\mathrm{CD} 4^{+}$cells (hematopoietic stem cells). As shown in Fig. $1 \mathrm{~A}$, the number of MK-like large cells increased in the presence of TPO. PPF (proplatelet formation; shown by arrow heads in Fig. 1A) was observed on day 7, and the quantity of PPF increased on day 9. The number of PLTs produced from the TPO-induced $\mathrm{CD} 34^{+}$cells increased exponentially up to day 9 (Fig. 1B). While very few $\mathrm{CD} 41^{+}$cells were detected at the beginning (day 2 following TPO-stimulation), both CD $41^{+}$and $\mathrm{CD} 41^{++}$cells markedly increased with incubation time (Fig. 1C). On day 9, most of the cells matured into CD $41^{++}$cells, indicating that $\mathrm{CD} 34^{+}$cells became $\mathrm{CD} 41^{+}$ MK cells within 5-7 d and then matured up to $9 \mathrm{~d}$ in response to TPO stimulation. Since TPO-stimulated CD34 ${ }^{+}$ cells on day 5 are available for the evaluation of PLT production, we employed the TPO-induced CD $34^{+}$cells on day 5.

Effect of hLF on PLT Production from Human MKs Derived from $\mathrm{CD}^{+} 4^{+}$Cells We examined the effect of hLF on PLT production from human MKs derived from $\mathrm{CD}^{+} 4^{+}$cells. As shown in Fig. 2, hLF significantly inhibited PLT production in a concentration dependent manner up to about $60 \%$ inhibition. No significant decrease in the total number of $\mathrm{MKs}$ in the dish was detected throughout this experiment (not shown), suggesting that the decrease in the number of PLT produced was not due to the cytotoxicity of hLF.

Effect of hLF on MK Maturation In order to elucidate the mechanism of the inhibition of PLT production by hLF, the effect of $\mathrm{hLF}$ on the process of MK maturation from $\mathrm{CD}_{3} 4^{+}$cells was examined. The intensity of expression of CD41 was used as an indication of maturation of MKs derived from $\mathrm{CD} 34^{+}$cells. As shown in Fig. 3A, the intensity of CD41 expression gradually increased with time of incubation with hLF. At day 8 (day 3 after addition of hLF), most of the cells became CD $41^{++}$cells. However hLF did not influence the intensity of CD41 expression of MKs. In addition, hLF did not significantly change the ploidy of MKs on day 6 
A
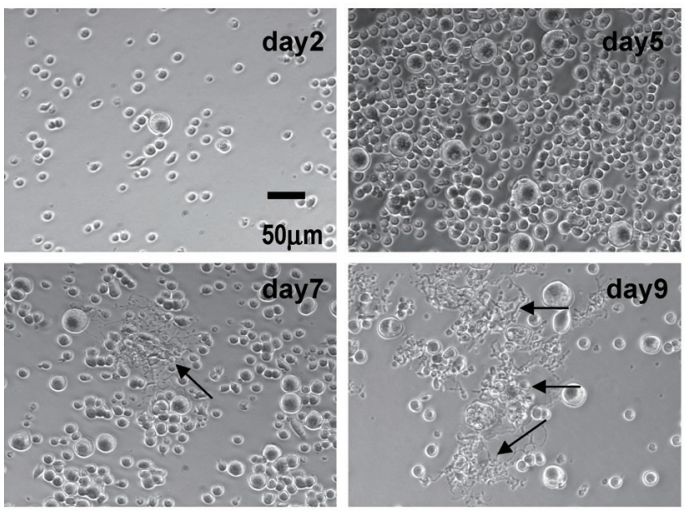

B

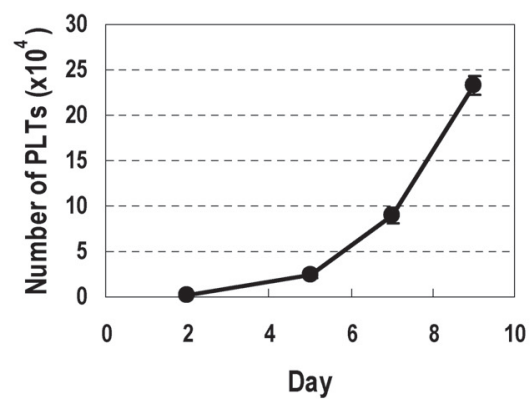

C
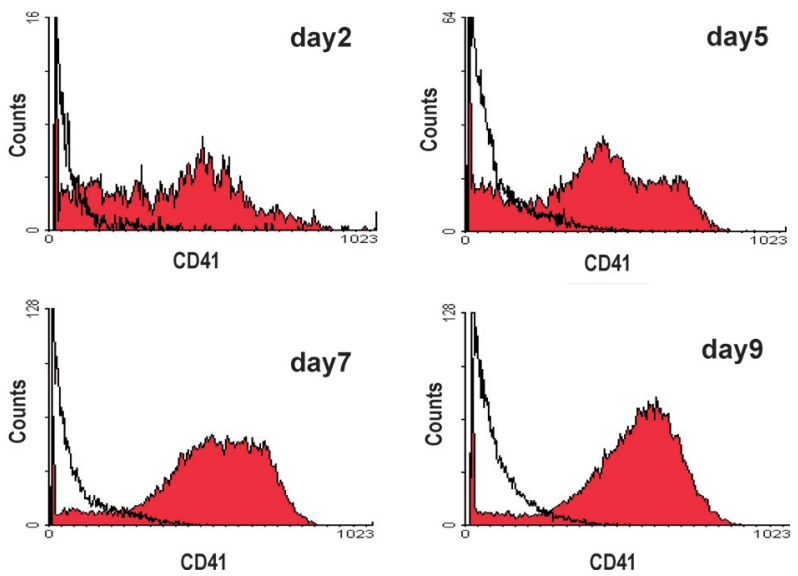

Fig. 1. Morphologic Changes and CD41 Expression during Megakaryopoiesis of TPO-Induced CD $34^{+}$Cells

$\mathrm{CD} 4^{+}$cells $\left(5 \times 10^{4}\right.$ cells $/ 500 \mu \mathrm{l} /$ well $)$ were cultured in the presence of TPO $(10 \mathrm{ng} / \mathrm{ml})$ in serum-free medium for up to $9 \mathrm{~d}$. (A) Photographs of day 2, 5, 7 and 9 . The number of MK-like-large cells increased with incubation time with TPO. PPFs (arrow) were observed after $7 \mathrm{~d}$ culture. (B) Culture-derived PLTs were counted by a flow cytometer, EPICS-XL. Results are expressed as means \pm S.E. of triplicates. (C) CD41 expression of TPO-induced $\mathrm{CD}^{+} 4^{+}$cells was analyzed by a flow cytometer EPICS-ELITE. The red area indicates CD41 positive cells and the bold line, isotypematched control.

(day 1 after addition of hLF), consisting of $2,4,8,16,32 \mathrm{~N}$ MK populations (Fig. 3B). These results indicate that hLF does not inhibit the maturation of MKs.

Effect of hLF on CFU-MK Next we examined the effect of LF on CFU-MK because CFU-MK is a precursor of immature MKs. hLF was incubated for $12 \mathrm{~d}$ with $\mathrm{CD} 34^{+}$ cells in the presence of TPO, IL-3 and IL-6 on collagenbased media. In the range of $1-100 \mu \mathrm{g} / \mathrm{ml}, \mathrm{hLF}$ did not in-

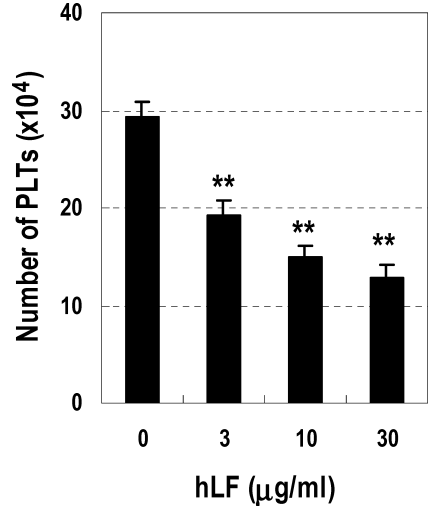

Fig. 2. Effect of hLF on PLT Production from Human MKs

$\mathrm{CD} 4^{+}$cells $\left(5 \times 10^{4}\right.$ cells $/ 500 \mu 1 /$ well $)$ were cultured in the presence of TPO $(10 \mathrm{ng} / \mathrm{ml})$ in serum-free medium for up to $5 \mathrm{~d}$. After $5 \mathrm{~d}$ culture, hLF was added to each well and incubated for up to $9 \mathrm{~d}$. PLT counts were analyzed on day 9 by a flow cytometer, EPICS-XL. $* * p<0.01$. Results are expressed as means \pm S.E. of triplicates.

\section{A}
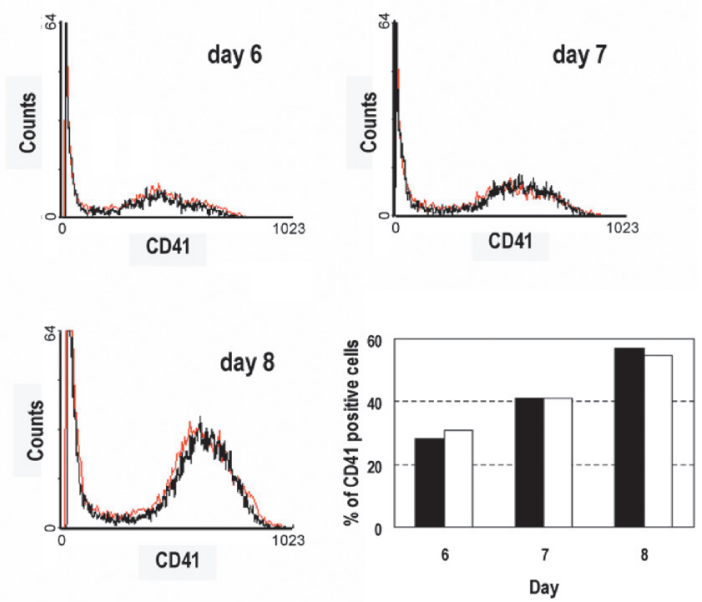

B
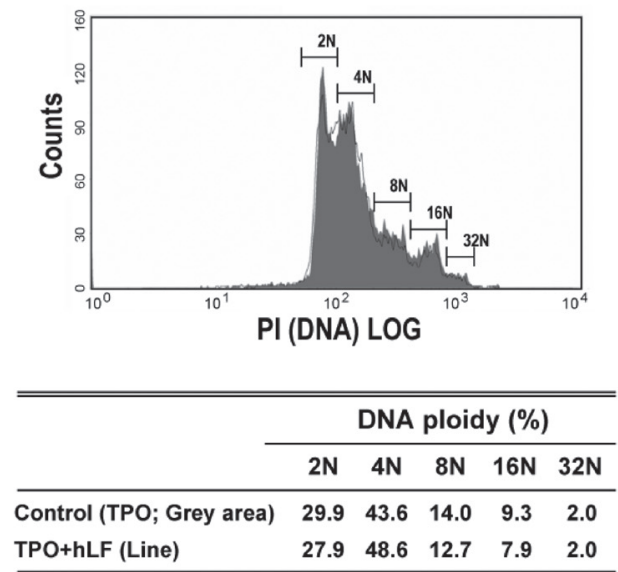

Fig. 3. Effect of hLF on MK Maturation

CD $34^{+}$cells $\left(5 \times 10^{4}\right.$ cells $/ 500 \mu \mathrm{l} /$ well $)$ were cultured in the presence of TPO $(10 \mathrm{ng} / \mathrm{ml})$ in serum-free medium up to day 5 . After $5 \mathrm{~d}$ culture, $\mathrm{hLF}$ was added to each well and incubated for up to $8 \mathrm{~d}$. (A) CD41 expression was analyzed on day 6, 7 and 8 by immunofluorescence staining of hLF-treated and untreated cells with FITC-conjugated anti-CD41 Ab using a flow cytometer, EPICS-ELITE. The red line indicates hLFtreated-cells and the black line, untreated cells. The percent of CD41 positive cells is shown in the right lower side graph. (B) Ploidy was analyzed on day 6 (after $24 \mathrm{~h}$ incubation) by immunofluorescence staining of hLF-treated and untreated cells with FITCconjugated anti-CD41 Ab and PI using a flow cytometer, FACSCalibur. The line indicates hLF-treated-cells and the grey area, untreated cells. 
hibit the number of CFU-MK (Fig. 4), suggesting that the inhibition of PLT production by hLF is not due to inhibition of CFU-MK by hLF.

Association of MK with Neutrophils in Mouse Bone Marrow (BM) It is known that LF is secreted from neutrophils. We examined the physiological relationship between neutrophils and MKs in mouse BM. H\&E-stained mouse BM tissue sections indicated that MKs are surrounded by many neutrophils and some MKs are located at sinusoids where MKs release PLTs to blood vessels (Fig. 5A). In addition, the mouse MK-enriched fraction contains aggregates of MKs with some neutrophils (Fig. 5B). These demonstrated that neutrophils associate with MK in BM. Therefore, it is possible that LF from neutrophils might regulate the PLT production from MKs.

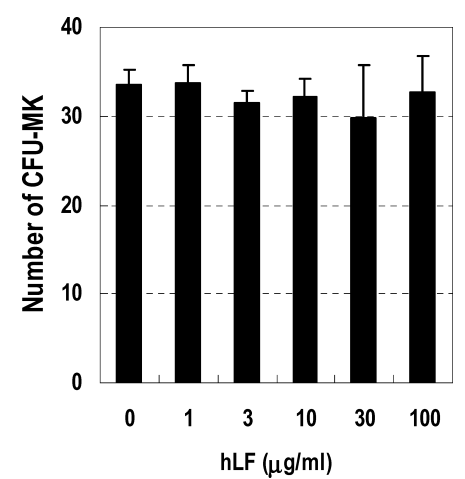

Fig. 4. Effect of hLF on CFU-MK

$2.5 \times 10^{3} \mathrm{CD} 34^{+}$cells were cultured with hLF in the presence of TPO, IL- 3 and IL-6 for $12 \mathrm{~d}$ in collagen-based, semisolid medium. After fixation, MKs were visualized with antibody against CD41a using alkaline phosphatase staining. Nuclei were stained with Evans blue. Stained colonies were enumerated on day 12 using an inverted microscope, defined as aggregates containing at least 3 large refractile cells. Results are expressed as means \pm S.E. of quadruplicate.

A

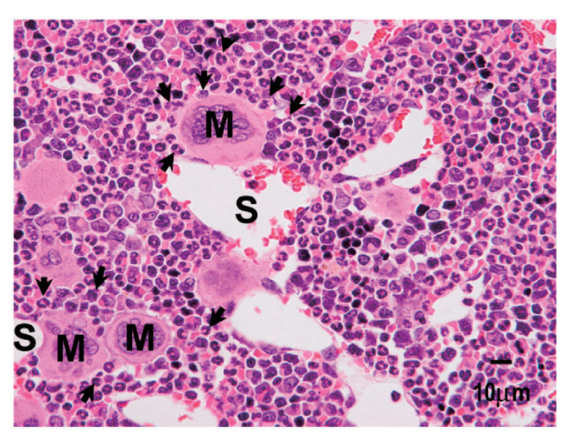

B

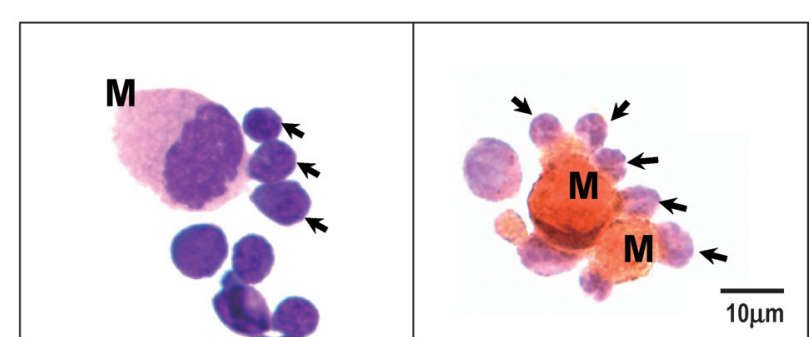

Fig. 5. MKs Interact with Neutrophils in Mouse BM

(A) H\&E stain of a bone marrow section in normal mice. Megakaryocytes (M) are surrounded by neutrophils (arrows) in bone marrow. S: sinusoid. (B) MK-enriched fraction $\left(\mathrm{CD} 41^{+} / 61^{+}\right.$fraction) smear from a normal mouse BM. Megakaryocytes (M) aggregate with neutrophils (arrows) (left: Wright-Giemsa stain, right: acetylcholine esterase stain).

\section{DISCUSSION}

In the present study, we found that LF showed an inhibitory effect on PLT production from immature MKs derived from TPO-induced CD34 ${ }^{+}$cells (Fig. 2). Therefore, it is thought that LF attenuates PLT production by either inhibition of maturation of immature MKs or inhibition of PLT production from matured MKs. The addition of LF did not affect the intensity of expression of CD41, a maturation marker of MKs, on TPO-induced CD34 ${ }^{+}$cells (Fig. 3A) nor polyploidyzation of TPO-induced $\mathrm{CD}^{2} 4^{+}$cells (Fig. 3B). These results suggest that LF does not influence the maturation steps of MKs. In addition, LF did not decrease CFUMK, a precursor of immature MKs (Fig. 4). Taking together, it is suggested that LF directly inhibits PLT production from matured MKs, but not megakaryopoiesis including CFU-MK and MK maturation. The schematic drawing for demonstrating a proposed mechanism is shown in Fig. 6.

It has been reported that the LF receptor is expressed on an immature MK cell line, the Dami cell. ${ }^{6}$ The cell line is a heterogeneous population consisting of a mixture of smaller, less differentiated blast cells and polyploid blast cells, and exhibits many of the morphological and biochemical characteristics of normal megakaryoblasts or immature MKs. ${ }^{22)}$ The timing of LF receptor expression on the Dami cell line, as described in Fig. 6, was reported after an MK specific marker, CD41 expression, and before GPIb expression which is also a MK specific marker expressed slightly later than CD41. ${ }^{23)}$ This, therefore, makes an assumption that LF contributes to the process of maturation of MKs, resulting in the inhibition of PLT production. However, in this study, we observed for the first time that LF directly inhibits the production of PLTs from matured MKs while it does not affect the proliferation/maturation process of human $\mathrm{CD} 4^{+}$cells to mature MKs (Fig. 6). The LF receptor expressed on immature MKs may contribute to other biological functions rather than the cellular maturation and proliferation.

To date, platelet factor (PF)-4 and neutrophil activating peptide (NAP)-2 are known as factors inhibiting megakaryopoiesis $^{24)}$ and are postulated as a feedback inhibition system of megakaryopoiesis. ${ }^{25}$ ) In the present study, we observed that neutrophils surrounded MKs in BM (Fig. 5A) and strongly aggregated with MKs (Fig. 5B). This observation was also noticed in previous reports ${ }^{26,27)}$ and suggests morphologically that neutrophils directly affect MKs in BM. In this study, we showed that LF derived from neutrophils acted biologically on MKs, resulting in inhibition of PLT produc-
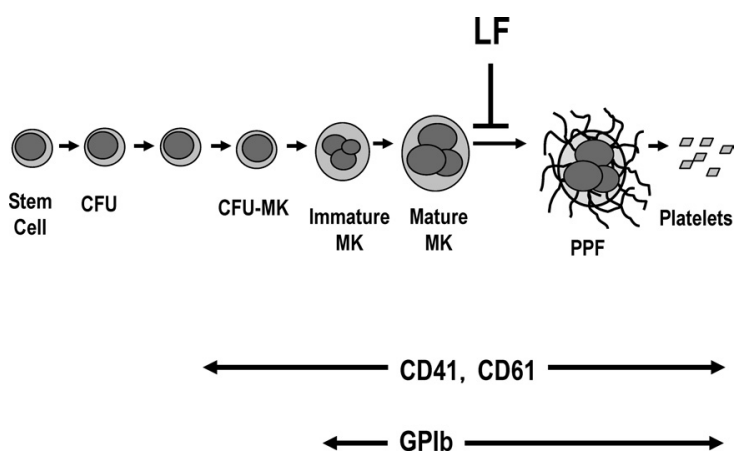

Fig. 6. A Proposed Mechanism for Inhibition of PLT Production by LF 
tion (Fig. 2). Recent research indicated that the chemokine SDF-1 derived from stroma cells and the growth factor FGF4 are necessary for MK recruitment to sinusoid endothelial cells and can help to recover the PLT count following myelosuppression, ${ }^{28)}$ which could be evidence that the BM stroma cells contribute to PPF and PLT release. Here, it was indicated that neutrophils in the BM may also be associated with PLT production. This may be help to elucidate the mechanism of PLT production which still requires to be clarified.

Pancytopenia, including neutropenia and thrombocytopenia, is one of most severe problems in cancer chemotherapy, ${ }^{29)}$ particularly as overcoming the delay of the recovery of the peripheral PLT count is necessary to improve the quality of life for patients. ${ }^{30)}$ For treatment of neutropenia, G-CSF is usually given after chemotherapy. ${ }^{31,32)}$ However, the recovery rate of peripheral PLTs is relatively slower than that of neutrophils. ${ }^{33)}$ It has been observed that the G-CSF treatment increases plasma LF level along with the increase in the neutrophil count. ${ }^{34)}$ Taken together with our results, we propose a novel hypothesis to explain the delay in the recovery of the PLT count after G-CSF treatment. Thus, LF is increased in the plasma after G-CSF treatment causing a delay in recovery of the PLT count as a result of stimulation of the LF receptor on matured MKs in BM. The avoidance of an increase of LF concentration after G-CSF treatment may be the key to achieving rapid recovery of PLT numbers in patients after chemotherapy.

In conclusion, this is the first report that LF acts directly on matured MKs, resulting in inhibition of PLT production.

Acknowledgement We would like to thank Ms Miho Kawasaki for help with statistical analysis.

\section{REFERENCES}

1) Suzuki Y. A., Shin K., Lonnerdal B., Biochemistry, 40, 15771-15779 (2001).

2) Baveye S., Elass E., Fernig D. G., Blanquart C., Mazurier J., Legrand D., Infect. Immun., 68, 6519-6525 (2000).

3) Grey A., Banovic T., Zhu Q., Watson M., Callon K., Palmano K., Ross J., Naot D., Reid I. R., Cornish J., Mol. Endocrinol., 18, 2268-2278 (2004).

4) Mazurier J., Legrand D., Leveugle B., Rochard E., Montreuil J., Spik G., Adv. Exp. Med. Biol., 357, 111-119 (1994).

5) Leveugle B., Mazurier J., Legrand D., Mazurier C., Montreuil J., Spik G., Eur. J. Biochem., 213, 1205-1211 (1993).

6) Nillesse N., Pierce A., Lecocq M., Benaissa M., Spik G., Biol. Cell,
82, 149-159 (1994).

7) Caccavo D., Sebastiani G. D., Di Monaco C., Guido F., Galeazzi M., Ferri G. M., Bonomo L., Afeltra A., Int. J. Clin. Lab. Res., 29, 30-35 (1999).

8) http://wombat.gnf.org/SymAtlas/

9) Chervenick P. A., Boggs D. R., Marsh J. C., Cartwright G. E., Wintrobe M. M., Am. J. Physiol., 215, 353-360 (1968).

10) Boxio R., Bossenmeyer-Pourie C., Steinckwich N., Dournon C., Nusse O., J. Leukoc. Biol., 75, 604-611 (2004).

11) Amouric M., Marvaldi J., Pichon J., Bellot F., Figarella C., In Vitro, 20, 543-548 (1984).

12) Bi B. Y., Lefebvre A. M., Dus D., Spik G., Mazurier J., Arch. Immunol. Ther. Exp., (Warsz), 45, 315-320 (1997).

13) Mazurier J., Legrand D., Hu W. L., Montreuil J., Spik G., Eur. J. Biochem., 179, 481-487 (1989).

14) Baveye S., Elass E., Mazurier J., Spik G., Legrand D., Clin. Chem. Lab. Med., 37, 281-286 (1999).

15) Ikeda M., Nozaki A., Sugiyama K., Tanaka T., Naganuma A., Tanaka K., Sekihara H., Shimotohno K., Saito M., Kato N., Virus Res., 66, $51-63(2000)$

16) Broxmeyer H. E., Int. J. Cell Cloning, 4, 378-405 (1986).

17) Sawatzki G., Rich I. N., Blood Cells, 15, 371-385 (1989).

18) Matsumura-Takeda K., Sogo S., Isakari Y., Harada Y., Nishioka K., Kawakami T., Ono T., Taki T., Stem. Cells, 25, 862-870 (2007).

19) Mathur A., Hong Y., Wang G., Erusalimsky J. D., Methods Mol. Biol., 272, 309-322 (2004).

20) Lannutti B. J., Drachman J. G., Blood, 103, 3736-3743 (2004).

21) Jackson C. W., Blood, 42, 413-421 (1973).

22) Greenberg S. M., Rosenthal D. S., Greeley T. A., Tantravahi R., Handin R. I., Blood, 72, 1968-1977 (1988).

23) Vinci G., Tabilio A., Deschamps J. F., Van Haeke D., Henri A., Guichard J., Tetteroo P., Lansdorp P. M., Hercend T., Vainchenker W., Breton-Gorius J., Br. J. Haematol., 56, 589-605 (1984).

24) Gewirtz A. M., Zhang J., Ratajczak J., Ratajczak M., Park K. S., Li C., Yan Z., Poncz M., Blood, 86, 2559-2567 (1995).

25) Oda M., Kurasawa Y., Todokoro K., Nagata Y., Genes Cells, 8, 9-15 (2003).

26) Travlos G. S., Toxicol. Pathol., 34, 548-565 (2006).

27) Rafii S., Shapiro F., Pettengell R., Ferris B., Nachman R. L., Moore M. A., Asch A. S., Blood, 86, 3353-3363 (1995).

28) Avecilla S. T., Hattori K., Heissig B., Tejada R., Liao F., Shido K., Jin D. K., Dias S., Zhang F., Hartman T. E., Hackett N. R., Crystal R. G., Witte L., Hicklin D. J., Bohlen P., Eaton D., Lyden D., de Sauvage F., Rafii S., Nat. Med., 10, 64-71 (2004).

29) Bodey G. P., Buckley M., Sathe Y. S., Freireich E. J., Ann. Intern. Med., 64, 328-340 (1966).

30) Kaushansky K., Hematol. Oncol. Clin. North. Am., 10, 431-455 (1996).

31) Heuser M., Ganser A., Bokemeyer C., Semin Hematol., 44, 148-156 (2007).

32) Dale D. C., Drugs, 62 (Suppl. 1), 1-15 (2002).

33) Kurzrock R., Clin. Cancer Res., 11, 1361-1367 (2005).

34) Olofsson T., Olsson I., Venge P., Elgefors B., Scand. J. Haematol., 18, $73-80$ (1977). 